\title{
CONCEITOS CENTRAIS E OS TENCIONAMENTOS EM TORNO DA LEI 4.771 DE 1965
}

\author{
João Paulo Peres Bezerra
}

RESUMO: Trazemos para o debate os resultados parciais de nossa investigação em nível de Mestrado intitulada "Gestão das Águas e Planejamento Ambiental da Bacia Hidrográfica do ribeirão Santo Antonio, Mirante do Paranapanema -São Paulo".

Temos como marco teórico a Geoecologia das Paisagens, na tentativa de aplicar esta visão teórica à estudos de planejamento ambiental de bacias hidrográficas. Com objetivos gerais da pesquisa, queremos adquirir conhecimentos sobre teorias e metodologias de planejamento ambiental, gestão de bacias hidrográficas Os objetivos específicos são: elaborar o inventário físico-territorial da bacia hidrográfica do Ribeirão Santo Antonio; identificar as principais unidades ambientais e seus processos socioambientais; diagnosticar qualitativamente as unidades ambientais da bacia hidrográfica do ribeirão Santo Antonio; elaborar e apresentar um prognóstico do estado ambiental da bacia; o acompanhamento das políticas públicas e de gestão ambiental e elaborar e apresentar propostas de melhoria e ordenamento ambiental da bacia do ribeirão Santo Antonio. Com o texto que se apresenta queremos debater resultados específicos da revisão bibliográfica e acompanhamento dos processos legislativos da legislação ambiental brasileira. Pontualmente vamos observar os escritos sobre Áreas de Preservação Permanente em nascentes e canais fluviais. Para tanto observamos a Lei Federal 4.771/1965 e os tencionamentos democráticos que buscam flexibilizar a legislação em questão, tais tencionamentos são sintetizados no texto aprovado em 8 de junho pela Comissão de Meio Ambiente e Desenvolvimento Sustentável. Tentaremos a partir de uma breve comparação e análise entre pontos específicos dos dois textos em questão buscando contribuir para o debate sobre a questão das Áreas de Preservação Permanentes. 


\section{1 Apresentação}

O objetivo deste texto é apresentar aos leitores, parte dos resultados já obtidos com o andamento de nosso projeto de investigação em nível de mestrado, . Inquietações intelectuais, a respeito do caminho das águas dentre o devir contemporâneo, nos impulsionaram para estes estudos através do recorte fisiográfico da bacia hidrográfica, e no ano de 2007 começamos os trabalhos em nível de bacharelado, com a bacia hidrográfica do ribeirão Santo Antonio.

Então construímos uma base de dados qualitativos e cartográficos que fornecem o alicerce para a nossa atual empreitada em nível de mestrado2009/2011. Tais estudos são realizados sob a orientação do Prof. Dr. Antonio Cezar Leal no contexto do Grupo de Pesquisa em Gestão Ambiental e Dinâmica Socioespacial e conta com o financiamento da CAPES. 
Figura 1: Localização da bacia do Santo Antonio.

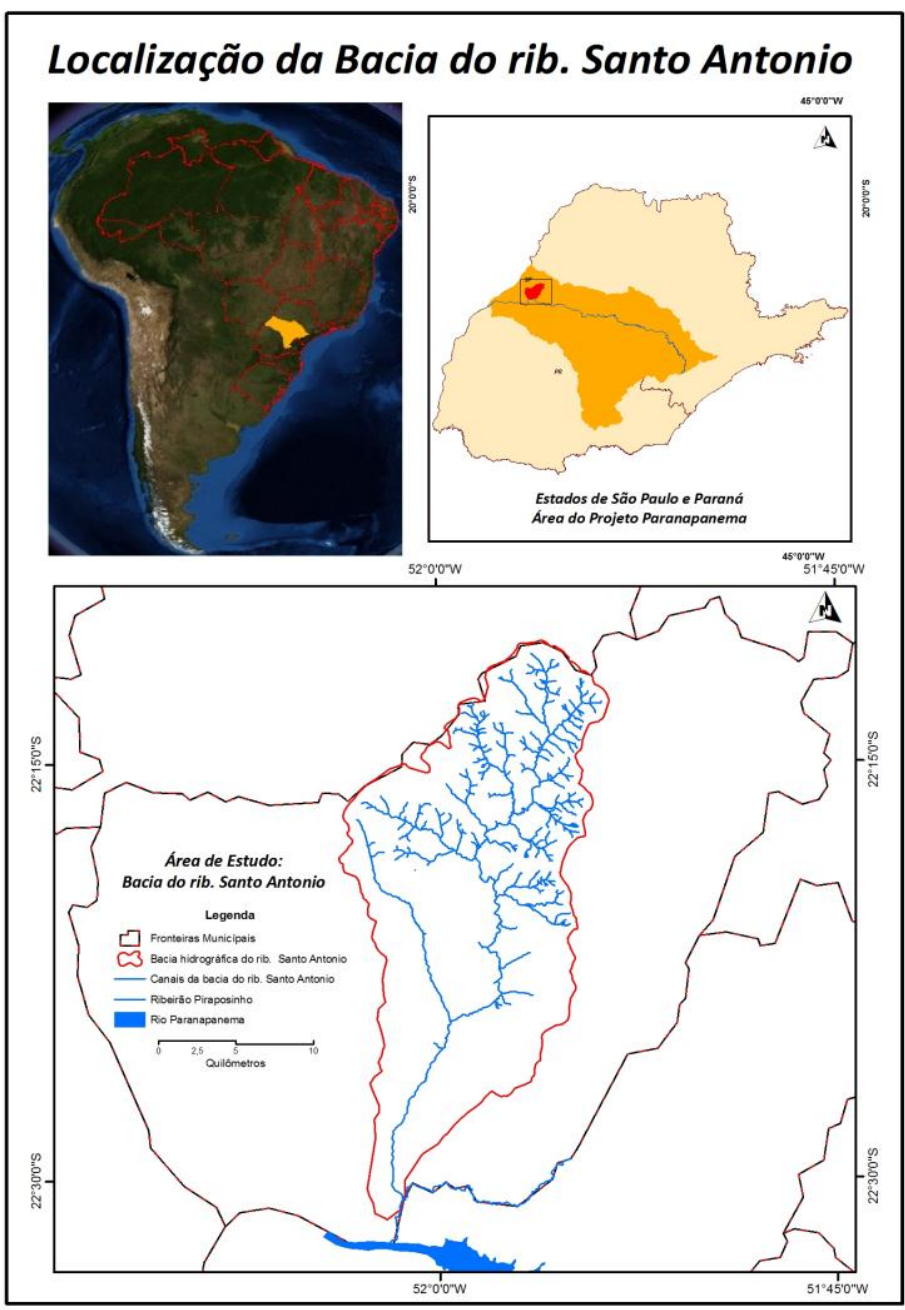

Org.\&Des.: (BEZERRA, J.P.P, 2010).

Nossa investigação tem como marco teórico a Geoecologia das Paisagens, nos moldes dos trabalhos de Leal, A.C.(1995), e se encontra em estágio de análise dos resultados parciais como mapas e cartas temáticas, a elaboração de textos autorais debatendo a bibliografia revisada e o diagnóstico de áreas de preservação permanente da bacia estudada.

Com os objetivos gerais da pesquisa, pretendemos aprimorar nossos conhecimentos sobre teorias e metodologias de planejamento ambiental e gestão de bacias hidrográficas. Nossos objetivos específicos são: elaborar o inventário físico-territorial da bacia hidrográfica do Ribeirão Santo Antonio; identificar as principais unidades ambientais e seus processos socioambientais; diagnosticar qualitativamente as unidades ambientais da bacia hidrográfica do 
ribeirão Santo Antonio; elaborar e apresentar um prognóstico do estado ambiental da bacia; o acompanhamento das políticas públicas e de gestão ambiental e elaborar e apresentar propostas de melhoria e ordenamento ambiental da bacia do ribeirão Santo Antonio.

No contexto de nossa pesquisa um marco legal fundamental é o Código Florestal brasileiro. Esse texto é visto por uma série de setores da economia e certos grupos acadêmicos, como um entrave ao desenvolvimento econômico brasileiro. Constituindo assim uma conflitualidade entre grupos de pensadores, técnicos ligados aos movimentos sociais organizados, grupos ambientalistas e acadêmicos que defendem o atual Código Florestal brasileiro e grupos ligados à lógica produtivista do agronegócio brasileiro que busca uma possível flexibilização da legislação ambiental.

Esta conjuntura técno-política é para nós um foco de conflitos imateriais que trazem possibilidades de avanços para a gestão ambiental brasileira, em todos os níveis de governo cujo debate é imprescindível.

Nesta oportunidade pretendemos debater alguns pontos centrais da questão, revendo especificidades da Lei 4.771/1965, quando trata das Áreas de Preservação Permanente e, o relatório recentemente aprovado pela Comissão de Meio Ambiente e Desenvolvimento Sustentável da câmera dos deputados federais.

A Comissão de Meio Ambiente e Desenvolvimento Sustentável, é uma comissão criada na esfera da câmera dos deputados federais, donde tivemos a aprovação do um texto que traz em seu bojo as possíveis alterações e revogações inerentes ao atual Código Florestal brasileiro e foi relatado pelo Dep. Federal Aldo Rebelo e foi ao público no dia 8 de junho de 2010.

Esse texto é resultado de onze anos de debates e entraves dentre setores ruralistas em conflito com ambientalistas e militantes de movimentos sócias. A argumentação dos que defendem esta flexibilização da legislação se pauta também no fato verídico de que camponeses e povos tradicionais são prejudicados pela legislação rigorosa, enquanto ambientalistas explicitam possibilidades legais como os Sistemas Agroflorestais para o uso racional de 
áreas de preservação permanentes para casos de ocupação consolidada ou atividades de baixo impacto das comunidades tradicionais.

Este debate vai muito além das APP's, chegando ao âmbito do modelo de desenvolvimento de nosso País, porém neste texto trataremos especificamente das APP's em canais fluviais na tentativa de melhor compreender as especificidades de processos legislativos e normativos inerentes ao ordenamento do território nacional.

\subsection{O Código Florestal}

No âmbito das políticas de gestão ambiental, surge um tensionamento muito debatido por toda a comunidade gestora, política e sociedade civil. $\mathrm{Na}$ tentativa de melhor compreender a questão gostaríamos de apresentar uma breve comparação entre as delimitações específicas de Áreas de Preservação Permanente em canais fluviais previstas no atual Código Florestal Brasileiro a Lei Federal 4.771 de setembro de 1965 e as possíveis alterações advindas de projetos de leis, dentre os quais o Projeto de Lei 1879 de 1999 que apensa outros projetos que foram apreciados e pela Comissão Permanente de Meio Ambiente e Desenvolvimento Sustentável sendo relatado pelo Deputado Federal Aldo Rebelo.

\subsection{A Lei Federal 4.711 e as possíveis mudanças}

O homem seja ele, camponês ou arrendatário, capitalista ou proletário, com origem no campo ou na grande cidade, comunista ou neoliberal, não pode viver sem a água. Por sua vez a água não pode ser pensada de maneira isolada da terra. A água, este elemento vital, tão comum para uns e de extrema raridade para outros deve ser objetivada a partir das questões relacionadas ao ordenamento territorial. 
Uma das normativas mais significativas de nosso ordenamento territorial é a Lei Federal 4.771 de setembro de 1965, preparado por um grupo de legisladores e técnicos altamente capacitados donde devemos citar o então desembargador da República Osny Duarte Pereira, um dedicado estudioso do que podemos chamar atualmente de legislação ambiental, tendo publicado em 1950 um estudo significativo a respeito de legislação florestal brasileira e mundial com o título Direito Florestal Brasileiro (REBELO, 2010).

O Código, ao proteger as florestas contidas no território nacional, que cumprem importantes funções ambientais, como o fluxo gênico e proteção da fauna, protege também o solo contra os processos erosivos, bem como as águas nos rios, lagos e reservatórios contra o assoreamento advindo dos processos de erosão (AHRENS, 2005).

Em seu primeiro artigo, o Código Florestal vem definir a obrigatoriedade do proprietário de imóveis rurais manterem e preservar áreas de vegetação, tendo como bem maior a manutenção da qualidade ambiental do País e ressalta em seu primeiro parágrafo a importância das matas e seu caráter de bem difuso, vejamos:

Art. $1^{\circ}$ As florestas existentes no território nacional e as demais formas de vegetação, reconhecidas de utilidade às terras que revestem, são bens de interesse comum a todos os habitantes do País, exercendo-se os direitos de propriedade, com as limitações que a legislação em geral e especialmente esta Lei estabelecem. (BRASIL, Código Florestal, 1965- 2006).

No texto aprovado em 8 de junho pela CMADS temos uma definição de APP que deve ser observada em detalhe pois mantém a definição apresentada pelo Código Florestal. Seu inciso segundo, parágrafos II e III, que trazem as definições de Área de Preservação Permanente:

\footnotetext{
II - área de preservação permanente: área protegida nos termos dos artigos 2PUoUP e $3 P \cup$ OUP desta Lei, coberta ou não por vegetação nativa, com a função ambiental de preservar os recursos hídricos, a paisagem, a estabilidade geológica, a biodiversidade, o fluxo gênico de fauna e flora, proteger o solo e assegurar o bem-estar das populações humanas;[...] (REBELO. A, 2010 p.246)
}

Com estas definições em mente partimos para explicitarmos as figuras legais que discorrem sobre a restauração de cobertura vegetal natural que por 
muitas vezes assume a forma de cobertura florestal. Ainda no Código Florestal temos a definição das áreas de preservação permanente e suas metragens:

Art. $2^{\circ}$ Consideram-se de preservação permanente, pelo só efeito desta Lei, as florestas e demais formas de vegetação natural situadas:

a-) ao longo dos rios ou de qualquer curso d'água desde o seu nível mais alto em faixa marginal cuja largura mínima será:" (Quadro 1)

Quadro 1: Metragem de Área de Preservação Permanente.

\begin{tabular}{|c|c|}
\hline Largura do Rio (m) & Largura de APP(m) \\
\hline Menos que 10. & 30 \\
\hline Entre 10 e 50. & 50 \\
\hline Entre 50 e 200 & 100 \\
\hline Entre 200 e 600 & 200 \\
\hline Acima de 600. & 500 \\
\hline
\end{tabular}

Fonte: Brasil, Código Florestal, 1965-2006. Org.: ( Bezerra, 2008).

$\mathrm{Na}$ tentativa de sintetizar o conteúdo dos parágrafos componentes da alínea a, apresentamos no (Quadro 1) a relação entre o comprimento do leito maior em eixo horizontal, e a respectiva classe métrica de Área de Preservação Permanente a ser aplicada conforme complementações ao Código Florestal dadas pela Lei complementar 7803 de 1989.

Ressaltamos que, a medição da espessura do leito maior sazonal de um dado rio, riacho ou ribeirão consiste na elaboração de estudo detalhado, que deve contemplar uma análise geomorfológica do perfil transversal do canal fluvial<>topo de vertente. Assim, as metragens citadas na no quadro acima devem ser de acordo com as definições conceituais elaboradas por disciplinas como a Geografia, Geomorfologia e Geomorfologia Fluvial. Vale ainda explicitar que a largura mínima do rio em projeção horizontal deve corresponder ao "leito maior sazonal" ou nível mais alto do rio.

Outra área core do sistema hidrográfico sabiamente protegida pela Lei 4.771/1965, enquadradas no Art. $2^{\circ}$ alínea c-) como áreas de preservação permanente, são os afloramentos de água. 


\section{FÓRUM AMBIENTAL DA ALTA PAULISTA}

Volume VI - Ano 2010

Instituição Organizadora: ANAP - Associação Amigos da Natureza da Alta Paulista

Como traz o Código Florestal, as áreas de nascentes perenes ou intermitentes -"olhos d'água" como prefere a língua popular-, devem ser protegidas como APP's cuja circunferência de cinqüenta metros de raio partindo de um ponto de nascente, formando uma área protetora do ponto aflorante. Ressaltamos ainda que o poder público pode vir a declarar uma dada área como Área de Preservação Permanente, tendo em vista o previsto do Artigo $3^{\circ}$ do Código Florestal.

Ao menos, no projeto aprovado pela CMADS as normativas forma mantidas. No texto que será apreciado pelos ilustríssimos deputados federais, o que nos importa esta no seu Art. 3ํㅡ ne Seção 1 do Cápitulo II. Vejamos:

Da Delimitação das Áreas de Preservação Permanente

Art. 3. Considera-se Área de Preservação Permanente, em zonas rurais ou urbanas, pelo só efeito desta Lei:

I - as faixas marginais de qualquer curso d'água natural, desde a borda do leito menor, em largura mínima de:

a) 15 (quinze) metros, para os cursos d'água de menos de 5 (cinco) metros de largura;

b) 30 (trinta) metros, para os cursos d'água que tenham de 5 (cinco) a 10 (dez) metros de largura;

c) 50 (cinquenta) metros, para os cursos d'água que tenham de 10 (dez) a 50 (cinquenta) metros de largura;

d) 100 (cem) metros, para os cursos d'água que tenham de 50 (cinquenta) a 200 (duzentos) metros de largura;

e) 200 (duzentos) metros, para os cursos d'água que tenham de 200 (duzentos) a 600 (seiscentos) metros de largura;

f) 500 (quinhentos) metros, para os cursos d'água que tenham largura superior a 600 (seiscentos) metros;

II - as áreas no entorno dos lagos e lagoas naturais, em faixa com largura mínima de: a) 100 (cem) metros, em zonas rurais, exceto para o corpo d'água com até 20 (vinte) hectares de superfície, cuja faixa marginal será de 50 (cinqüenta) metros;

b) 30 (trinta) metros, em zonas urbanas; (REBELO. A, 2010 p.248)

Podemos observar uma primeira diferença estrutural na forma proposta pelo relatório em questão. No texto da Lei 4.771 temos a previsão da área de APP a partir do leito maior sazonal, um conceito da geomorfologia fluvial de fundamental importância para a sustentabilidade dos sistemas hidrológicos abertos como uma dada bacia hidrográfica. O leito maior sazonal pode ser sintetizado no perfil longitudinal a seguir:

Figura 1: Modelo dos tipos de leitos fluviais. 


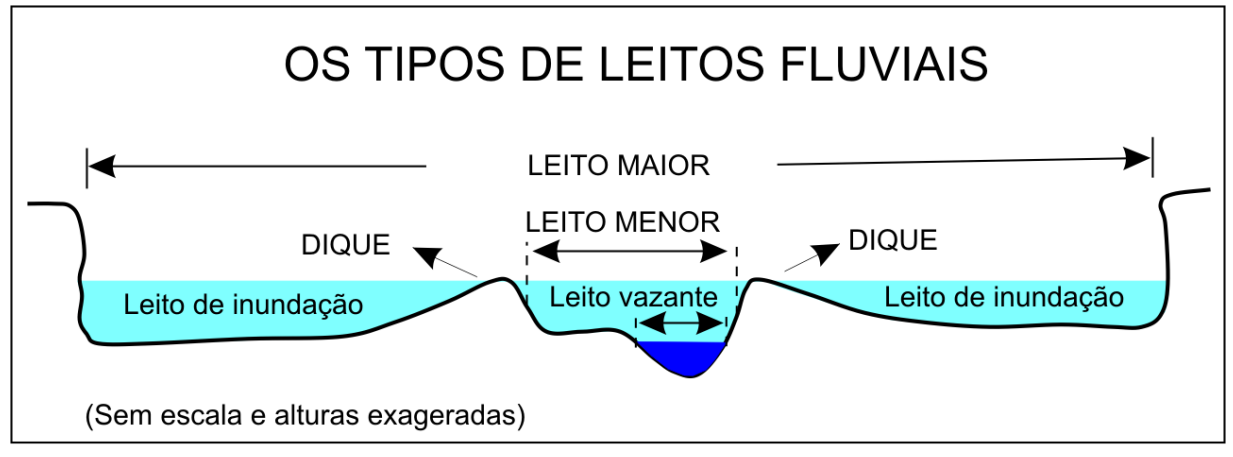

Adp. De Christofolettı (1981, p. 60).

Des.: Christofoletti (1981). Org: Boin. M. (2006).

Já no novo texto temos a demarcação prevista do leito menor, ou seja, o leito vazante do canal fluvial como vemos no parágrafo I do Artigo 3ํㅜ, conforme citação acima. Apenas este ponto já é passível de observações uma vez que o leito menor é suscetível a mudanças em seu fluxo perene, com variações em sua vazão. Cuja forma geomorfológica básica do canal, sua largura e profundidade e suas margens sofrem mutações físicas e linminológicas de acordo com o regime pluviométrico, condições de infiltração e percolagem da água no solo das áreas a montante e intervenções humanas.

Este fato nos leva a crer que o texto aprovado em 8 de junho de 2010 pela Comissão de Meio Ambiente e Desenvolvimento Sustentável apresenta debilidades conceituais.

Um ponto crítico esta nas classes de metragem das áreas de preservação permanentes, onde o texto aprovado pela CMADS traz uma nova classe de APP, contando com 15 metros de largura marginal a partir do leito menor para os canais fluviais que apresentarem 5 metros de ou menos de espessura do leito menor. Para as espessuras restantes as espessuras permanecem a mesma, ou seja: $5-10 \mathrm{~m}=30 \mathrm{mAPP} ; 10-50 \mathrm{~m}=50 \mathrm{mAPP}$; 50 200m=100mAPP; 200-600m=200mAPP; +600m=500mAPP.

Estas metragens podem ser reduzidas de acordo com um dispositivo criado e previsto no texto que repassa o direito aos poderes Estaduais e Municipais a possibilidade de redução de até $50 \%$ do previsto no projeto de lei em questão. Vejamos o texto a seguir: 
$\S 1^{\circ}$ Os estados e o Distrito Federal, poderão, por lei, aumentar ou reduzir ematé $50 \%$ (cinqüenta por cento) as faixas mínimas previstas nos incisos I, II, e IV do caput, desde que fundamentadas em recomendações do Zoneamento Ecológico Econômico, previsto no inciso II do art. 9o da Lei no 6.938, de 31 de agosto de 1981, do Plano de Recursos Hídricos elaborado para a bacia Hidrográfica e aprovado na forma do art. $7^{\circ}$ da Lei $n^{\circ}$ 9.433, de 8 de janeiro de 1997 ou de estudos técnicos específicos de instituição pública especializada.

(REBELO. A, 2010.)

Este dispositivo irá permitir um grande avanço das terras agricultáveis, porém teremos a redução das capacidades de resiliência ecossistêmica, delegando a incerteza de sustentabilidade geoecológica das cabeceiras de drenagem e planícies aluviais, prejudicando o fluxo genético, a regeneração natural das matas ciliares.

Como podemos notar o texto acima permite que os Estados e Municípios legislem sobre a questão, e possibilita a redução da metragem de APP em uma dada área municipal ou estadual. Neste ponto devemos lembrar que os limites administrativos nem sempre são os mesmos que os limites fisiográficos de uma bacia hidrográfica, que muitas vezes os canais fluviais transpõem limites municipais e estaduais criando assim um possível conflito para a gestão dos recursos hídricos em suas múltiplas escalas operacionais.

Devemos ressaltar que esta presente no texto do projeto de lei, a necessidade de observação dos planos de Recursos Hídricos de bacias hidrográficas, este ponto reforça a gestão dos recursos hídricos e contribui para a consolidação da gestão de recursos hídricos como setor protagonista, juntamente com outros setores da gestão ambiental no Brasil.

\section{4 Considerações Finais}

Devemos citar os importantes trabalhos realizados pelo mestre Aziz Nacib Ab'Saber, que nestes últimos tempos vem escrevendo sobre seus posicionamentos a respeito destes tencionamentos sobre o Código Florestal Brasileiro. Importante ressaltar a participação efetiva da Sociedade Civil através de das Organizações Não Governamentais e Universidades e 
Movimentos Sociais. Vejamos de forma muito sintética algumas palavras do tão renomado Geógrafo Ab'Saber:

\begin{abstract}
O primeiro grande erro dos que no momento lideram a revisão do Código Florestal brasileiro - a favor de classes sociais privilegiadas - diz respeito à chamada estadualização dos fatos ecológicos de seu território específico. Sem lembrar que as delicadíssimas questões referentes à progressividade do desmatamento exigem ações conjuntas dos órgãos federais específicos, em conjunto com órgãos estaduais similares, uma Polícia Federal rural e o Exército Brasileiro. Tudo conectado ainda com autoridades municipais, que têm muito a aprender com um Código novo que envolva todos os macrobiomas do país e os mini-biomas que os pontilham, com especial atenção para as faixas litorâneas, faixas de contato entre as áreas nucleares de cada domínio morfoclimático e fitogeográfico do território. (AB'SABER, 2010).
\end{abstract}

Como podemos notar estamos diante de um debate político onde classes e grupos econômicos disputam com argumentações técnicas a aprovação de leis e normativas ordenamentos territoriais que viabilizam ou dificultam a implantação efetiva de um certo modelo de desenvolvimento econômico.

Entendemos que a função da Sociedade Civil esta na atenta observação, proposição e cobrança sobre o legislativo e executivo, buscando políticas públicas e tentar levar para espaços de debates democráticos os mecanismos e instrumentos de gestão.

$\mathrm{Na}$ atual conjuntura, pensamos na importância de distinguirmos quem é o camponês ou agricultor familiar dos grandes empresários e grupos transnacionais da agroindústria. Buscando uma equação ecologicamente sustentável, economicamente viável e culturalmente adequada.

\title{
Referencias Bibliográficas
}

AB'SABER, Aziz Nacib. Do Código Florestal para o Código da Biodiversidade. In: Revista Digital Evolverde. Disponível em: <http://www.envolverde.com.br/index.php?edt=29\&sAutor=7437> Acessado em: 15/06/2010. 
AHRENS, Sergio. Sobre a Legislação Aplicavél à Restauração à Restauração de Florestas de Preservação Permanente e Reserva Legal. In: GALVÃO,A.P.M; PORFIRIO-DA-SILVA, V. Restauração Florestal: Fundamentos e Estudo de Caso . Colombo-Embrapa, Paraná. 2005.

BRASIL. Lei Federal 4.771 setembro de 1965 Código Florestal Brasileiro. Disponível em <http://www.planalto.gov.br/ccivil_03/Leis/L4771.htm> Acessado em: 05/05/2010.

CHRISTOFOLETTI, A. Geomorfologia. São Paulo: Edgard Blücher, 1981.

LEAL, A.C. Meio ambiente e urbanização na microbacia do Areia Branca Campinas - São Paulo. Dissertação (Mestrado em Geociências e Meio Ambiente) - Instituto de Geociências e Ciências Exatas, Universidade Estadual Paulista. Rio Claro, 1995.

REBELO. A. Parecer do relator deputado federal Aldo Rebelo (PCdoB-SP) ao Projeto de Lei no 1876/99 e apensados. Câmara dos Deputados Federais 8 de junho de 2010.2 Disponível em <www.camara.gov.br/sileg/integras/777725.pdf> Acessado em: 10/62010. 